\title{
NEW EUROPEAN SOLUTIONS FOR STRENGTHENING COMPETITIVENESS IN DIGITAL MARKETS
}

\author{
Slavica Purić, Associate \\ Law Firm Pierstone Brussels, \\ Avenue de la Toison d'Or 22, 1050 Ixelles, Belgium \\ slavica.puric@pierstone.com
}

\begin{abstract}
The assumption that undertakings in digital markets will, as in "traditional" ones, compete among each other to provide always better and diverse products and services, and that users will be allowed to easily find these products and services, compare them and choose those that suit them best, turned out to be incorrect. The same happened with the assumption that existing EU and national competition law will be able to effectively address issues that occur in digital markets and that are (usually) a consequence of the anti-competitive behavior of the biggest digital undertakings. The purpose of the paper is to examine why and how these digital undertakings cope to escape control of the competition authorities, and what are new solutions that are proposed at the EU and national level to strengthen competitiveness in digital markets. Therefore, we will firstly single out few main characteristics of digital markets, then identify challenges that competition law faces in these markets due to the presented characteristics. In the fourth and the main part of the paper, we will present key provisions proposed in the draft Digital Markets Act to complement competition law and ensure contestable and fair digital markets across the EU. We will thereafter present some of the new national competition rules recently adopted in Germany, which are similar to those proposed under the draft Digital Markets Act.
\end{abstract}

Keywords: Digital Market, Competition Law, Digital Markets Act, Gatekeeper, Merger

\section{INTRODUCTION}

For the last decade, at least, we are witnessing how digitalization changes the world we have known so far in every single aspect: the way we work, communicate, receive information, etc. Digitalization brought numerous innovations, new products and new services, and has become an integral part of our daily lives. This has become particularly true with the beginning of the COVID-19 outbreak 
and the shutdown of many countries around the globe. Digital infrastructure and sophisticated digital solutions have played a central role to keep the economies running; and not only the economies but our social life as well.

Apart from the many benefits that digital innovation has undoubtedly brought, we are aware of certain concerns and issues that come with them as well. For instance, there is a fear of the loss of privacy, misuse of data, cyber-attacks, reinforcement of economic inequality by new technologies and so on. On top of that, there is an increasing anxiety about the ever-growing digital companies and their dominance in the market.

At the beginning of the expansion of the Internet, it was expected that digital undertakings will compete to provide as good and as diverse services as possible, and the users will be allowed to compare these services and easily switch from one provider to another. However, the market developed in a completely different way, meaning that today only a few largest digital undertakings have become the new gateways through which people use the Internet. Most of the Western population uses Google to find information and content on the Internet, Facebook/WhatsApp to connect and communicate, Amazon to shop online, etc. ${ }^{1}$ The influence of these large digital undertakings can cause various economic, political and social issues.

This paper will focus only on issues that large digital undertakings cause to the competitiveness in digital markets. Namely, these undertakings are left on their own terms and enabled to misuse entrenched positions in the market, since they manage to escape the control and eventual intervention by competition authorities. This is possible because digital markets have some specific characteristics that differentiate them from "traditional" markets (to which competition rules can apply adequately) and that are particularly beneficial for large digital undertakings. We will firstly observe these characteristics through the eyes of an undertaking that provides services in the digital market and does not belong to the group of a few largest digital undertakings. This undertaking will be referred to as "undertaking X" in the paper. Thereafter, we will see that, as a result of identified characteristics, competition authorities face challenges regarding the definition of the relevant market, assessment of the market power of the undertaking, assessment of the anti-competitive behavior of the undertaking and merger control. Many legislators are trying to figure out how to tackle these challenges. In that regard, the European Commission (Commission) proposed the draft Digital Markets Act

Crémer, J.; de Montjoye Y.A.; Schweitzer, H., Report Competition policy for the digital era, 2019, p.13 
Regulation (DMA) to secure that "what is illegal offline is equally illegal online". In light of the DMA's objectives to tackle issues that cannot be (effectively) addressed by the EU and national competition law and secure fair and contestable digital markets, we will analyze provisions that contain criteria for designating gatekeepers and the obligations that should be directly imposed on them. The purpose of this analysis is to see how proposed solutions complement competition rules and enable regulating large digital undertakings' behavior, despite identified challenges. In addition, new national competition rules adopted in Germany that are similar to solutions offered in the DMA will be presented. We will try to assess whether and how these new EU and national solutions can tame digital undertakings that act as rule-makers and gateway for one group of users to reach another in digital markets.

\section{CHARACTERISTICS OF DIGITAL MARKETS}

Digital markets are usually understood as a meeting place for supply and demand through the digital platforms. ${ }^{3}$ They have a set of characteristics ${ }^{4}$ that are very specific and that distinguish them from "traditional" markets ${ }^{5}$. We will present below four main characteristics, which are closely connected to each other.

$2 \quad$ Europe fit for the Digital Age: Commission proposes new rules for digital platforms, Press release as of 15 December 2020, [ec.europa.eu/commission/presscorner/detail/en/ip_20_2347], Accessed 15 March.

3 Tavassi, M. A., Bellomo, G., Chapter 19: Online Markets, Geoblocking and Competition, in Muscolo, G., Tavassi, M.A., The Interplay Between Competition Law and Intellectual Property: An International Perspective, International Competition Law Series, Volume 77, 2019, p. 278.

4 There are different classifications of characteristics of the digital market. For instance, Hoernig recognizes eight types of characteristics (i) returns to scale and scope, (ii) network effects, (iii) multi-sidedness, (iv) data-driven, (v) feedback mechanisms, (vi) ecosystems and conglomerates, (vii) algorithmic decision-making, (viii) gig economy. (Hoernig, S., The Digital Markets and Services Act: Context and Outlook? Policy Paper for the Institute of Public Policy Lisbon, 2021, p. 4-6) The DMA, which is the subject of this paper, identifies six of them: (i) the size, including turnover and market capitalisation, operations and position of the provider of core platform services; (ii) the number of business users depending on the core platform service to reach end users and the number of end users; (iii) entry barriers derived from network effects and data-driven advantages, in particular in relation to the provider's access to and collection of personal and non-personal data or analytics capabilities; (iv) scale and scope effects the provider benefits from, including with regard to data; (v) business user or end user lock-in; (vi) other structural market characteristics. The Report "Competition policy for the digital era" focuses on three features: (i) extreme returns to scale; (ii) network externalities; and (iii) the role of data (Crémer, J.; de Montjoye Y.A.; Schweitzer, H., op.cit., note 1, p.2)

5 However, some authors argue that digital markets are not so different from traditional markets (for instance, see Massarotto, G., From Standard Oil to Google: How the Role of Antitrust Law Has Changed, World Competition, Issue 3, 2018, p. 395-418.) 
The first characteristic of digital markets is known as an extreme return to scale and, in practice, it means that the cost of providing services significantly falls as the undertaking expands (on the other side, for "traditional markets", the dimensional growth is profitable only up to a certain point (marginality criteria)). ${ }^{6}$ In fact, the costs of providing services online can be so low that they are disproportional to the number of users, which enables the biggest digital undertakings to offer their services for a very low price or even for free. Offering services for free to pull up end users is common among digital undertakings that use advertising as the main source of business revenue, because the more users undertakings have, the more attractive they will be for new advertisers. The increase in number of users and revenue secures to these large digital undertakings a significant competitive advantage compared to the other (existing or new) undertakings, including undertaking X, which has lower disproportionality between costs of providing services and the number of users to whom these services are provided. ${ }^{7}$

The second characteristic is reflected in two- or multi-sidedness. ${ }^{8}$ By saying this, we mean in the first place on digital undertakings that have a capacity to connect many business users with many end users through their two- or multi-sided platforms. ${ }^{9}$ It is interesting to note that some multi-sided platforms have built ecosystems around their core activities, including services they provide in competition with their business users. Such ecosystems enable digital undertakings to create a large unrivalled user base ${ }^{10}$, i.e., to gather more users' data and use that data to improve and personalize services (these benefits will be analyzed in the following two paragraphs). Consequently, the value of each product and service offered in the digital ecosystem is higher than it would be if the same product or service is offered separately. Being aware of that, undertaking X will be interested to be a part of a digital ecosystem and cooperate with other undertakings by complementing each other's services. A problem arises if undertaking X provides services that do not complement but compete with services offered by another undertaking in the digital ecosystem, and that another undertaking is, for instance, Google. In that case, undertaking $\mathrm{X}$ will be in a disadvantaged position because (i) if decides to stay in the digital ecosystem, it will have to "fight" against the so-called tech giant,

6 Tavassi, M. A., Bellomo, G., op.cit., note 3, p. 279.

7 Jenny, F. Competition Law and Digital Ecosystems: Learning To Walk Before We Run, 2021, [https://ssrn. com/abstract=3776274], p. 1, Accessed 5 March 2021

8 Parker, G.; Petropoulos, G.; Van Alstyne, M.W., Digital Platforms and Antitrust, 2020, [https://ssrn. com/abstract=3608397], p. 5-6, Accessed 20 March 2021

9 Two- or multi-sided platforms bring two or more groups of users, e.g. buyers and sellers, on the same place (platform) and enable those users to connect with each other.

10 Bongartz, P., Langenstein, S., Podszun, R., The Digital Markets Act: Moving from Competition Law to Regulation for Large Gatekeepers, Journal of European Consumer and Market Law, Issue 2, 2021, p.61 
and (ii) if decides to offer services outside of the digital ecosystem, undertaking X will not be able to profit from the benefits mentioned above and its services will therefore be less valuable for users. ${ }^{11}$

The strong network effect presents the third characteristic of digital markets. This means that the convenience of using services provided by the digital undertaking increases as the number of users of services rises. For example, users benefit the situation when as many as possible persons join Facebook because they can easily connect and communicate, there is more content available and advanced options are offered to users. Let us now imagine that undertaking X starts offering social media platform services as well - no matter how innovative its services may be, it will be extremely difficult to compete with Facebook. Undertaking X will have to not only invest in services to offer better quality at lower prices (or for free) but also to convince users to change the provider, i.e. to start using its services. As a result, undertaking $\mathrm{X}$ and many other similar to it will be discouraged to enter or invest in the digital market where there is already a dominant digital player ${ }^{12}$.

Finally, digital markets are data-driven, meaning that data plays an extremely important role. In fact, almost all of the listed characteristics in one way or another lead to data, i.e. collecting and storing a large amount of users' data by digital undertakings, in a course of providing their services. Collected data are further used to analyze users' behavior online and have an insight into their needs and preferences. ${ }^{13}$ Output received from this analysis will serve for improving existing services and tailoring them to better satisfy users' needs or for eventually developing new services. We explained that undertaking $\mathrm{X}$ can have access to (some of) this data if it is a part of the digital ecosystem. Otherwise, it will gather significantly less data if it does not have many users; hence, it will be in a disadvantaged position again.

\section{HOW CHARACTERISTICS OF DIGITAL MARKETS CHALLENGE EXISTING COMPETITION RULES?}

We can conclude from the previous part of the paper that characteristics of digital markets (extreme return to scale, two- or multi-sidedness, strong network effect and the role of data) can create significant benefits for undertakings operating therein, especially for those undertakings that have an entrenched position and for whom mentioned characteristics are the most relevant. We can also conclude that

\footnotetext{
11 Jenny, F., op.cit., note 4, p. 5

12 Parker, G.; Petropoulos, G.; Van Alstyne, M.W., op.cit., note 5, p. 6

13 Crémer, J.; de Montjoye Y.A.; Schweitzer, H., op.cit., note 1, p. 2
} 
smaller and new undertakings are not left with many options - they can either try to challenge the large one, which is exhausting and resource-consuming, sometimes almost impossible, or they can decide to pull back from the market or provide only those services that do not compete but rather complement services of the large digital undertakings. Ultimately, some undertakings may recognize and invest in a niche market, which would be a part of the larger market but with its own features. We will go back to these undertakings when analyzing mergers in digital markets.

Under the articles 101 and 102 TFEU, the competition authorities can only intervene ex post, i.e. after they assess on a case-by-case basis that the conditions for intervention are met. ${ }^{14}$ This means that the competition authority cannot simply assume that a provider of online platform services enjoys a dominant position within the meaning of Article 102 TFEU, even when it has a large turnover and a large number of business or end users. It should rather first define the relevant market and evaluate its features to find whether such a platform is dominant or not. If the competition authority finds that the platform at issue has a dominant position in the market, it has to show that platform at issue abused such position.

However, in the digital markets, it is particularly difficult for the competition authorities to make the assessments properly on whether the conditions for their intervention are met. In that regard, we can identify four main challenges that the competition authorities face in digital markets: (i) defining the relevant market ${ }^{15}$, (ii) assessing the market power, (iii) assessing the anti-competitive behavior of the undertaking, and (iv) tracking mergers that are not notifiable under the EU law and assessing whether notified mergers can significantly impede effective competition.

Defining the relevant market is the first step in analyzing a case regarding the anti-competitive agreements, abuse of a dominant position or merger control. Given the multi-sided characteristic of digital markets, adopting a narrow definition of the relevant market could result in missing important insights that need to be considered for the analysis. To be specific, one individual side of a platform may not be defined as a relevant market because the platform does not intend to maximize its profits on that side independently of the other side; it rather takes into consideration the interaction between the users on both sides. However, if

14 For more information on constrains on competition authorities see: Ibáñez Colomo, P., The Draft Digital Markets Act: A Legal and Institutional Analysis, 2021, [https://ssrn.com/abstract=3790276], p. 14-18, Accessed 5 April 2021

15 For more information on this topic see: A new competition framework for the digital economy, Report by the Commission "Competition Law 4.0", Federal Ministry for Economic Affairs and Energy of Germany, 2019, p. 27-30 and Challenges for Competition Policy in a Digitalised Economy, Study for the ECON Committee, 2015, p. 52-58. 
the competition authority assumes that the entire platform should be covered by definition, the assessment of the market power will be more complex due to the broadness of the definition. ${ }^{16}$

Second, as the assessment of the market power depends on the definition of the relevant market, it is not surprising that the traditional measures for market power, such as market shares and concentration ratios based on market shares, do not work very well too. ${ }^{17}$ In that regard, it is worth noting that the question of whether data can contribute to gain market power in products and services has been much debated recently, and the relevance of this question has also been recognized by the German and French competition authorities in a joint report on data and its implications for Competition Law. ${ }^{18}$

Third, regarding the assessment of the anti-competitive behavior of an undertaking, Articles 101 and 102 TFEU provides an exemplary list of anti-competitive multilateral and unilateral behavior, which list can be adapted to the specificities of digital markets. However, dominance in the digital market is not the same as the one in the "traditional" market in a way that it may not have the same negative consequences for consumers and may be compatible with active competition for the market. ${ }^{19}$ Moreover, application of both articles requires extensive investigations of facts on a case-by-case basis, which may be time and resource-consuming and not effective enough in fast-changing and unpredictable digital markets. ${ }^{20}$

Last but surely not less important challenge that competition law faces is related to mergers in digital markets. We will analyze two key issues in that regard: first, the issue of mergers that escape the competition authorities' control because they do not trigger traditional merger notification thresholds due to low annual turnover (acquisition of small but promising companies, mostly start-ups) and second, the issue of assessing of whether the notified merger in the digital market is pro- or anti-competitive. ${ }^{21}$

16 Robertson, V., Antitrust Law and Digital Markets: A Guide to the European Competition Law Experience in the Digital Economy, 2020, [https://ssrn.com/abstract=3631002], p. 6, Accessed 22 March 2021

17 Parker, G.; Petropoulos, G.; Van Alstyne, M.W., op.cit., note 5, p. 4

18 Wasastjerna, M., Chapter 4: Interlinkage Between Competition and Data Privacy, in Competition, Data and Privacy in the Digital Economy: Towards a Privacy Dimension in Competition Policy?, International Competition Law Series, Volume 86, 2020, p. 117 - 160.

19 Robertson, V., op.cit., note 14, p. 11-14

20 Motta, M.; Peitz, M., Intervention triggers and underlying theories of harm, Expert advice for the Impact Assessment of a New Competition Tool, 2020, p. 31-33.

21 Holmström, M.; Padilla, J.; Stitzing, R.; Sääskilahti, P., Killer Acquisitions? The Debate on Merger Control for Digital Markets in Yearbook of the Finnish Competition Law Association, 2018, [https://ssrn. com/abstract=3465454], p. 12-19, Accessed 5 April 2021 
Regarding the first issue (acquisition of small but promising companies), it is crucial to note that the EU Merger Regulation sets up quite high thresholds for merger notifications to competition authorities. ${ }^{22}$ In numerous cases in the digital environment, these thresholds will not be reached, leading to a situation where many acquisitions of small potential competitors by larger undertakings are "invisible" for authorities. For the sake of illustration how frequent these mergers are, since 2008, Google has acquired more than 150 companies and Facebook more than 70 companies without any merger control, while in both cases many of them were potential competitors in certain segments. ${ }^{23}$ Namely, some smaller companies, particularly start-ups that provide services in niche markets, as mentioned at the beginning of this part of the paper, have the potential to become successful, attract users or develop innovative technologies and know-how. The potential of a start-up is not always reflected in its turnover because, in the beginning, many founders invest in improving their product instead of collecting profit. Some of them do so hoping that another large and successful undertaking will recognize its potential and buy it under favorable conditions. The acquisition can be a "good deal" for founders (monetization of their business idea) and for large undertakings (early elimination of potential competitor), while at the same time it can be detrimental to innovation and competition.

As for the second issue (assessment of whether the notified merger in the digital market is pro- or anti-competitive), when the merger is notified, the authority has to conduct a comprehensive investigation to assess whether it is anti-competitive. In accordance with the Merger Regulation, the Commission will prohibit the concentration if assesses that it significantly impedes effective competition. While some acquisitions are only realized to eliminate potential competitors, most of them would have a goal to improve and/or complement existing services. This is particularly true when the acquisition target does not operate in the acquirer's core market but rather in a separate market. Also, due to characteristics of the digital markets (notably network effects and extreme return to scale), increasing the size of the undertaking enables the quality of its services to increase as well, and that benefit passes on to consumers. ${ }^{24}$ Since merger control intervenes ex ante to protect the future competitiveness, competition authorities have to compare the expected effect of a merger at issue with the expected developments on the identi-

22 Council Regulation 2004/139/EC on the control of concentrations between undertakings (the EC Merger Regulation) [2004] OJ L 24

23 Chatillon, A.; Henno, O., op.cit., note 11, p. 68-69

24 The importance of data, another characteristic of digital markets, is also relevant for mergers in a way that the competition authority should assess if (i) the acquirer will be able to access data gathered and accumulated by the acquisition target and (ii) if the merge will negatively affect the privacy protection and the quality of service provided by merged undertakings. (Jenny, F., op.cit., note 4, p. 21). 
fied relevant market, which is particularly difficult in the digital market. Only after that, it can decide whether to approve, with or without commitments or to prohibit the merger at issue.

Most of the challenges mentioned above are not likely to occur in "traditional" markets; even if they do, existing competition rules provide solid mechanisms to address the issue and work toward a fair and competitive market. Namely, the principal aims of the competition law are to enhance the efficiency of the market and to protect consumers from harm through anticompetitive behavior. ${ }^{25}$ In the digital environment, it is far more difficult to reach these objectives. While competition has traditionally been understood as the presence of a large number of undertakings producing similar products and competing to acquire market share through lower prices and innovation, this is often not feasible in the digital environment. As it was noticed in the French Senat's Report, players with considerable market power in digital markets manage to escape the historical concepts and instruments of competition policy. ${ }^{26}$

\section{NEW PROPOSALS AND LEGISLATION TO ADDRESS CHALLENGES IN DIGITAL MARKETS}

\subsection{A new proposal on the EU level}

In order to catch up with today's digital reality, the European Commission published a proposal for the Digital Markets Act (DMA) ${ }^{27}$ at the end of last year. According to the DMA, weak contestability and unfair practices are mainly related to highly-concentrated multi-sided platform services, where a few large digital

25 It has even been argued that the ultimate purpose of competition law is to ensure the satisfaction of all reasonable wishes of consumers, being it of price or non-price nature, such as variety, innovation and privacy protection (See Privacy and competitiveness in the age of big data: The interplay between data protection, competition law and consumer protection in the Digital Economy, Preliminary Opinion of the European Data Protection Supervisor, 2014, p. 17). In that regard, though with the less supportive attitude, Van den Bergh and Weber conclude "the recent Facebook case has further complicated the current state of German competition law by intermingling competition goals with concerns of privacy protection" (Van den Bergh, R., Weber, F., The German Facebook Saga: Abuse of Dominance or Abuse of Competition Law?, World Competition, Issue 1, 2021, p. 30.) - this statement will be elaborated in chapter 4.3 of the paper.

26 To support this assertion, it states that the control thresholds can fail to detect (and eventually prevent) so-called predatory acquisitions and the approach to dominance in terms of price does not take into account the advantages related to data ownership or network effects. (Chatillon, A.; Henno, O., Rapport d'information, Sénat $N^{\circ}$ 603, [www.senat.fr/rap/r19-603/r19-6030.html], p. 67, Accessed 13 April 2021.

27 Proposal for a Regulation of the European Parliament and of the Council on contestable and fair markets in the digital sector (Digital Markets Act) COM/2020/842 final 
platforms act as gateways for business users to reach their customers (end users) and their power can easily be misused.

Following provisions contained in the DMA are considered to be a good solution for effective and timely intervention in digital markets: (i) an exhaustive list of core platform services, (ii) requirements for the designation of providers of core platform services as gatekeepers and specific criteria for assessing whether they are met, and (iii) directly applicable obligations for designated gatekeepers.

Core platform services currently listed in the DMA are online intermediation services, online search engines, operating systems, online social networking, video sharing platform services, number-independent interpersonal communication services, cloud computing services and online advertising services. Following a market investigation, the Commission will have a possibility to update this list.

An undertaking that provides core platform services does not necessarily have to be qualified as a gatekeeper, unless if: (i) has a significant impact on the internal market, (ii) operates as an important gateway for business users to reach end users, and (iii) either (a) enjoys an entrenched and durable position or (b) is expected to enjoy such a position in the near future.

To avoid unnecessarily broad interpretation of these three objective requirements, the DMA contains quantitative thresholds for assessing whether to designate an undertaking as a gatekeeper. First, an undertaking will be presumed to have a significant impact on the internal market if its annual turnover or the average market capitalization meets the threshold ${ }^{28}$ set up in the DMA. Second, an undertaking operates as an important gateway if it has more than 45 million monthly active end users established or located in the EU (corresponding to $10 \%$ of the entire population of the EU) and more than 10000 yearly active business users established in the EU. The third requirement is fulfilled if an undertaking has reached the number of users specified above in the last three financial years (iii(a)), or it is likely to reach a specified number and ensure an entrenched and durable position in the near future.

The Commission is provided with a certain level of discretion in assessing whether an undertaking has a gatekeeper role even if it does not satisfy all of the quantitative thresholds. Such an assessment has to be based on the market investigation,

28 Article 3 paragraph 2 point (a) of the DMA: the undertaking to which a provider of core platform services belong should achieve an annual turnover equal to or above EUR 6.5 billion in the last three financial years, or where the average market capitalization or the equivalent fair market value of the undertaking to which it belongs amounted to at least EUR 65 billion in the last financial year, and it provides a core platform service in at least three Member States. 
by taking into account these thresholds and the level of innovation, the quality of digital products and services, the characteristics of digital markets that are particularly relevant for the undertaking at issues, as well as high growth rates and similar indicators. ${ }^{29}$ This is one of the important novelties that the DMA brings because it enables an early intervention against undertakings that have not yet become entrenched.

The third set of provisions we identified as relevant for the complementation of competition rules consists of the list of directly applicable obligations that should regulate the conduct of gatekeepers on an ongoing basis. ${ }^{30}$ These obligations can be grouped into two categories: the self-executing obligation (listed in Article 5 of the DMA) and obligations that should be further specified based on the regulatory dialog with gatekeepers (Article 6 of the DMA). Restraining from combining personal data from different sources and from requiring users to register with one core platform service as a condition to accessing any other are some of the obligations falling in the first category, while examples of obligations to be further specified are not to use data generated through activities of the business users on the platform to then compete with them, not to treat more favorably in ranking own services or products compared to similar services or products of third parties (so-called self-preferencing), to enable data portability and real-time access to data generated through the users' activities, etc. It should be noted that undertakings designated as gatekeepers under (iii(b)) will not be subject to all obligations that are imposed on gatekeepers who have already an entrenched and durable position, but only those obligations that are necessary and appropriate to avoid the qualified risk of unfair conditions and practices.

Based on the presented sets of provisions, we can conclude that the main complement to the competition law that the DMA offers is reflected in its approach that should prevent the occurrence of anti-competitive behaviors. Such prevention is

29 Article 3 paragraph 6 of the DMA: (a) the size, including turnover and market capitalization, operations and position of the provider of core platform services; (b) the number of business users depending on the core platform service to reach end users and the number of end users; (c) entry barriers derived from network effects and data-driven advantages, in particular in relation to the provider's access to and collection of personal and non-personal data or analytics capabilities; (d) scale and scope effects the provider benefits from, including with regard to data; (e) business user or end user lock-in and (f) other structural market characteristics.

30 Some authors critique that the DMA lacks a principled approach and that obligations imposed on gatekeepers, in particular, look like a random selection of past and ongoing cases. It is proposed to follow three principles when setting up the obligations: contestability of markets, fairness of intermediation and independence of decision. For more information, see: Podszun, R.; Bongartz, P.; Langenstein, S., Proposals on How to Improve the Digital Markets Act, 2021, [https://ssrn.com/abstract=3788571], p. 4-6, Accessed 2 April 
enabled by imposing specific obligation directly on all undertakings that fulfill the objective requirements to be designated as gatekeepers, plus undertakings that do not fulfill the requirements but the Commission assessed that they should be designated as such. Two groups of obligations imposed on gatekeepers under the DMA can be seen as specific case examples of abusive behavior. ${ }^{31}$

The DMA does not provide guidance on how to deal with previously specified challenges (definition of the relevant market, assessment of the market power and the anti-competitive behavior of the undertaking), but rather oblige all gatekeepers to behave or not behave in a certain way that should ensure competitiveness in the market. In an ideal scenario, each undertaking that provides core platform services in the digital market and qualifies as gatekeeper will respect the obligations contained in the DMA. If it fails to do so, it will be fined under the DMA. This approach should enable the Commission to save resources and to avoid defining relevant markets, assessing market dominance or examining whether these practices can restrict competition. Moreover, the gatekeeper cannot challenge its regulatory duties by claiming that, even though it qualifies to be designated as gatekeeper, its conduct does not have anti-competitive effects because the DMA says that this would not be relevant. ${ }^{32}$

Regarding the forth challenge to competition law, i.e. merger control, the DMA introduces an obligatory notification rule. Namely, the gatekeeper is obliged to notify the Commission of any intended merger that involves another provider of core platform services or any other services provided in the digital sector, irrespective of whether it would be notifiable to relevant authority under the EU or national merger rules. The submitted notification should, among others, contain the information on annual turnover for the acquisition target, the core platform service provider's annual turnover, number of yearly active business users and monthly active end users, as well as the rationale of the intended concentration.

The introduced mandatory notifications for gatekeepers of any acquisition in digital markets aim at solving the first issue we have identified within the merger challenge. In other words, this obligation can address the issue of acquiring companies

31 Leistner, M., The Commission's vision for Europe's Digital Future: Proposals for the Data Governance Act, the Digital Markets Act and the Digital Services Act - A critical primer, 2021, [https://ssrn.com/ abstract=3789041], p. 3, Accessed 5 April 2021

32 Authors of The European Proposal for a Digital Markets Act - A First Assessment, Centre on Regulation in Europe, January 2021, recommend introducing the explicit possibility for the gatekeeper to defense in order to escape the application of some obligations by demonstrating that its practices are not unfair, nor do they harm market contestability. Moreover, they recommend providing the Commission with the possibility of not imposing a specific obligation to a specific regulated gatekeeper at all, if this would be justified because there is no measure which would be effective and proportionate (p.7). 
and start-ups with high potential but low turnover, and enable tracking of the developments on the market while ensuring more control. However, it does neither guarantee fewer (approved) mergers of this type nor a more adequate assessment of whether a merger is pro-competitive or not.

Also, the DMA does not deal with the case when a gatekeeper merges with an undertaking outside of the digital market. It indeed aims at regulating the online behavior of gatekeepers; still, it is noteworthy that this kind of merger may still have an impact on the strengthening of gatekeeper's position in the (both) market(s). These are not frequent (yet) but should not be neglected, because a gatekeeper can benefit from digital markets' characteristics (particularly from the use of gathered users' data) to expand its services to "traditional" markets as well. Take for an example the case of Amazon buying the Whole Food Market. ${ }^{33}$

\subsection{New provisions on the national level - a case of Germany}

A necessity for adaptation of the competition law to this new digital environment has been recognized worldwide. Aware of the fact that different issues occurring in the digital market that are related to its specific characteristics cannot be (effectively) covered by the existing competition rules, several countries are putting forward their proposals. Some EU Member States are also advancing with their laws, thus contributing to a regulatory fragmentation within the internal market. Germany, as a leading country when it comes to preventive rules for large digital undertakings $^{34}$, has recently taken the biggest step forward.

Few weeks after the DMA is proposed, Germany updated its national competition law by adopting the $10^{\text {th }}$ amendment on the Act against Restraints of Competition $^{35}$ and provisions that mostly cover the same issues as the DMA. Specifically, the German Federal Cartel Office (germ. Bundeskartellamt) (FCO) is now enabled to determine by an order that certain undertakings have paramount cross-market

33 Amazon, a large core platform services provider that usually first comes to mind when talking about gatekeepers, has bought a couple of years ago a leading organic food supermarket based in the US. This deal benefits Amazon in many ways, including an entry into the offline grocery store business and access to a huge amount of data.

34 The German competition authority has already gone ahead when assessing anti-competitive conduct in the digital markets - for more information on this topic see: Schneider,G., Testing Art. 102 TFEU in the Digital Marketplace: Insights from the Bundeskartellamt's investigation against Facebook, Journal of European Competition Law \& Practice, Oxford University Press, Vol. 9, Issue 4, 2018. Also, in 2017, Germany introduced additional notification thresholds based on transaction value by adopting the $9^{\text {th }}$ amendment on the Act against Restraints of Competition.

35 Gesetz gegen Wettbewerbsbeschränkungen in der Fassung der Bekanntmachung vom 26. Juni 2013 (BGBl. I S. 1750, 3245) (German Act against Restraints of Competition (German Act)) 
significance for competition ${ }^{36}$, which is similar to the Commission's designation of gatekeepers. It is important to note that adopted rules apply to all undertakings that have a strong market position on two or more markets, but they should primarily tackle large digital platforms. There are no objective requirements or quantitative thresholds to be met; it is up to the FCO to conduct a case-by-case investigation and assess if undertaking at issue has such paramount significance. Criteria that should be taken into account when making an assessment include undertaking's market dominance in one or more markets, financial strength and access to other resources, access to competitively relevant data and similar. The order can be effective for a maximum of five years and it can be disputed before the Federal Court of Justice, which will act as the first and final instance. ${ }^{37}$

Undertakings that are determined by order to have paramount cross-market significance for the competition can be obliged by the FCO to restrain from engaging in certain activities. ${ }^{38}$ This is another similarity with the DMA and the list of obligations provided therein. For instance, the undertaking at issue should not take measures that directly or indirectly hinder competitors on markets where this undertaking can rapidly expand its position, even without being dominant. This practically means that the FCO can prohibit (ex-ante) the undertaking for performing certain activities even in markets where the undertaking is not dominant, thus prevent abusive expansion into non-dominated markets. However, the FCO will not prohibit any of these conducts if the undertaking successfully proves that its conduct is objectively justified (as mentioned, gatekeepers do not have this possibility under the DMA).

Regarding the merger control, the update that is relevant for the paper and similar to the provision in the DMA, relates to the new possibility for the FCO to conduct sector investigation and require by order the undertaking to notify any merger ${ }^{39}$ in one or more specified sector if (a) the undertaking has achieved worldwide sales of more than 500 million euros in the last fiscal year, (b) there are objectively reasonable grounds for believing that future mergers could significantly impede effective domestic competition in the specified sector and (c) the undertaking has a share of at least $15 \%$ of the supply of or demand for goods or services in Germany in the specified sector. ${ }^{40}$

\footnotetext{
36 Article 19a(1) of the German Act

37 Article 73(5) of the German Act

38 Article $19 \mathrm{a}(2)$ of the German Act

39 However, a merger where acquisition target has not achieved sales of more than 2 million euros in the last financial year and has not generated more than two thirds of its sales in Germany does not have to be notified. Article 39a(2) of the German Act

40 Article 39a(1) of the German Act
} 


\subsection{Relationship between the DMA and (national) competition policy}

The Recital 10 DMA tries to draw a line between the legal interests of the proposed regulation and the competition policy by stating that Article 101 and 102 TFEU and national competition rules have as their objective the protection of undistorted competition on any given market, while the DMA aims at ensuring "that markets where gatekeepers are present are and remain contestable and fair, independently from the actual, likely or presumed effects of the conduct of a given gatekeeper covered by this Regulation on competition on a given market."

Considering that services provided by gatekeepers have a cross-border nature and can be provided in all Member States, one objective of the DMA is to prevent regulatory fragmentation that would undermine the functioning of the single market. Therefore, it prohibits in Article 1(5) the Member States from imposing further obligations on gatekeepers for the purpose of ensuring contestable and fair markets. In other words, Member States can impose any obligation compatible with the EU law on undertakings, including providers of core platform services, as long as these providers do not qualify to have a status of gatekeeper under the DMA.

The very next paragraph (Article 1(6)) states that the DMA is without prejudice to the application of Articles 101 and 102 TFEU and respective national rules. Basedow interprets this provision in a way that it is without prejudice to the application of national competition rules regarding not only undertakings that do not fulfill objective requirements to be designated as gatekeepers under the DMA, but as well to those undertakings that fulfill objective requirements (designated gatekeepers). ${ }^{41}$

Given the characteristics of digital markets and challenges caused by them, the competition authority will not often find that the large digital undertaking's conduct is anti-competitive and decide to apply competition rules. Yet, one of the rare cases happened in 2019 when the German competition authority found that Facebook has breached national competition rules that prohibit the abuse of a dominant position by using the terms of use that provide for the processing and use of user data that is collected when the Internet is used independently of the Facebook platform. ${ }^{42}$ This case was both welcomed and criticized at the same

$41 \quad$ Basedow, J., Das Rad neu erfunden: Zum Vorschlag für einen Digital Markets Act (Reinventing the Wheel: The Proposal for a Digital Markets Act), Zeitschrift für Europäisches Privatrecht, Vol. 29, 2021, forthcoming, Max Planck Private Law Research Paper No. 21/2, [https://ssrn.com/abstract=3773711], p. 6, Accessed 6 April.

42 The Federal Court of Justice provisionally confirms the allegation of abuse of a dominant market position by Facebook by qualifying the lack of choice on the part of consumers, and not the violation of 
time. ${ }^{43}$ Additionally, we see that new national competition rules in Germany prohibit certain forms of unilateral conduct even in markets where the undertaking is not dominant. These rules will be applied to undertakings with paramount crossmarket significance for competition and, having in mind criteria to assess if an undertaking has such significance, we can say with certainty that gatekeepers will be covered by these rules. It is not clear from the current DMA text weather these rules (and potentially similar ones in other Member States), which are part of the national competition law, would remain valid after the enactment of the future DMA Regulation. ${ }^{44}$ If not, new German solutions might lose their importance, since they are adopted above all to regulate the conduct of undertakings acting as gatekeepers.

To conclude, although the DMA is envisaged as an ex-ante regulatory tool to address the issues that cannot be (effectively) tackled by the EU and national competition policies and should be without prejudice to the application of these policies, parallel existence of this regulation and competition law could lead to over - or double-enforcement - against the same undertaking for the same behavior. In order to avoid the overlapping, Georgieva suggests both temporal and conceptual separation of the ex-ante DMA regulation and ex-post competition enforcement on digital markets. ${ }^{45}$

\section{CONCLUSION}

Ever-growing and fast-developing digital markets, together with undertakings operating therein, set a difficult task in front of competition authorities - they have to ensure effective competition, but they are disabled to effectively apply competition rules. Challenges that competition authorities face when try to assess

data protection laws, as an infringement of German competition law. Press release,

[www.bundesgerichtshof.de/SharedDocs/Pressemitteilungen/DE/2020/2020080.html], Accessed 10 April 2021

43 Authors Van den Bergh and Weber (Van den Bergh, R., Weber, F., op.cit., p. 39-40.) underline the principle "that different goals require the use of different instruments, non-competition goals must be achieved by legal rules outside the scope of competition law", referring to the Facebook decision where the violation of data protection laws was qualified as an abuse of dominant position. They argue that this finding substantially waters down the causation requirement (between market dominance and the use of unfair contract terms, in the case at issue).

44 Bongartz, P., Langenstein, S., Podszun, R., op.cit., note 10, p. 67. Authors of The European Proposal for a Digital Markets Act - A First Assessment (op.cit., note 32, p.10) interpret the Article 1(5) DMA in a way that new rules adopted within the 10th Amendment of the German law can remain applicable next to the DMA, once enacted, as these new rules are based on national competition law.

45 Georgieva, Z., The Digital Markets Act Proposal of the European Commission: Ex-ante Regulation, Infused with Competition Principles, European Papers, Vol. 6, No 1, 2021, p. 25-28, ISSN 2499-8249 - doi: $10.15166 / 2499-8249 / 448$ 
whether anti-competitive conduct occurred and their intervention is needed, are connected with specific characteristics of digital markets, i.e., extreme return to scale, multi-sidedness, network effect and a role of data.

Many countries worldwide endeavor to fully understand how these markets function and anticipate in which direction they will evolve, to find appropriate solutions to establish control over them. In particular, legislators intend to regulate the behavior of large digital undertakings that connect many users, make other undertakings dependent on them and present a serious threat to competitiveness in digital markets.

The European legislator proposes a new ex ante approach to these undertakings that are designated as gatekeepers. This approach implies that the Commission, as a competition authority, does not have to deal with the definition of the relevant market, measurement of the market power of the gatekeeper in the defined market, nor with the assessment of whether the gatekeeper's conduct is anti-competitive. Instead, it can impose the obligation specified in the DMA to undertakings solely on the basis that they meet requirements to be designated as gatekeepers. These obligations are created in a way that, if gatekeepers behave accordingly, they will significantly decrease the likeliness for anti-competitive conduct to occur and for competition to be jeopardized in digital markets. Therefore, we conclude that the DMA does not offer guidance on how to deal with challenges but rather complements competition law by offering solutions on how to avoid dealing with them.

Regarding new German competition rules, we see that they are mainly adopted with the objective to regulate the behavior of undertakings with paramount crossmarket significance for competition, and they are also based on ex ante approach. Unlike the Commission, the FCO has to conduct an investigation prior to issuing an order and imposing obligations on undertakings, including the obligation to notify any merger in the specified sector(s).

Finally, we see that the DMA's prohibition to the Member States from imposing further obligations on gatekeepers can raise come concerns. Yet, we should remember that Germany will have significant influence in finalizing and adopting the DMA Regulation, so we can expect those obligations to be contained in the regulation and those envisaged by new German competition rules will not be (too) diverse. Moreover, the FCO's experience in the application of new rules in digital markets will show how effective these rules are, and it might serve as an example of what (not) to include in the final DMA version. 


\section{REFERENCES}

\section{BOOKS AND ARTICLES}

1. Basedow, J., Das Rad neu erfunden: Zum Vorschlag für einen Digital Markets Act (Reinventing the Wheel: The Proposal for a Digital Markets Act), Zeitschrift für Europäisches Privatrecht, Vol. 29, 2021, forthcoming, Max Planck Private Law Research Paper No. 21/2, [https:// ssrn.com/abstract=3773711], , Accessed 6 April 2021.

2. Bongartz, P., Langenstein, S., Podszun, R., The Digital Markets Act: Moving from Competition Law to Regulation for Large Gatekeepers, Journal of European Consumer and Market Law, Issue 2, 2021, p. 60-67.

3. Bongartz, P.; Langenstein, S.; Podszun, R., Proposals on How to Improve the Digital Markets Act, 2021, [https://ssrn.com/abstract=3788571], Accessed 2 April 2021.

4. Georgieva, Z., The Digital Markets Act Proposal of the European Commission: Ex-ante Regulation, Infused with Competition Principles, European Papers, Vol. 6, No 1, 2021, p. 25-28, ISSN 2499-8249 - doi: 10.15166/2499-8249/448.

5. Holmström, M.; Padilla, J.; Stitzing, R.; Sääskilahti, P., Killer Acquisitions? The Debate on Merger Control for Digital Markets in 2018 Yearbook of the Finnish Competition Law Association, 2018, [https://ssrn.com/abstract=3465454], Accessed 5 April 2021.

6. Ibánez Colomo, P., The Draft Digital Markets Act: A Legal and Institutional Analysis, 2021, [https://ssrn.com/abstract=3790276], Accessed 5 April 2021.

7. Jenny, F. Competition Law and Digital Ecosystems: Learning To Walk Before We Run, 2021, [https://ssrn.com/abstract=3776274], Accessed 5 March 2021.

8. Leistner, M., The Commission's vision for Europe's Digital Future: Proposals for the Data Governance Act, the Digital Markets Act and the Digital Services Act - A critical primer, 2021, [https://ssrn.com/abstract=3789041], Accessed 5 April 2021.

9. Massarotto, G., From Standard Oil to Google: How the Role of Antitrust Law Has Changed, World Competition, Issue 3, 2018, p. 395-418.

10. Parker, G.; Petropoulos, G.; Van Alstyne, M.W., Digital Platforms and Antitrust, 2020, [https://ssrn.com/abstract=3608397], Accessed 20 March 2021.

11. Robertson, V., Antitrust Law and Digital Markets: A Guide to the European Competition Law Experience in the Digital Economy, 2020, [https://ssrn.com/abstract=3631002], Accessed 22 March 2021.

12. Schneider,G., Testing Art. 102 TFEU in the Digital Marketplace: Insights from the Bundeskartellamt's investigation against Facebook, Journal of European Competition Law \& Practice, Oxford University Press, Vol. 9, Issue 4, 2018.

13. Tavassi, M. A., Bellomo, G., Chapter 19: Online Markets, Geoblocking and Competition, in Muscolo, G., Tavassi, M.A., The Interplay Between Competition Law and Intellectual Property: An International Perspective, International Competition Law Series, Volume 77, 2019 , p. $275-298$.

14. Van den Bergh, R., Weber, F., The German Facebook Saga: Abuse of Dominance or Abuse of Competition Law? World Competition, Issue 1, 2021, p. 29-52. 
15. Wasastjerna, M., Chapter 4: Interlinkage Between Competition and Data Privacy, in Competition, Data and Privacy in the Digital Economy: Towards a Privacy Dimension in Competition Policy? International Competition Law Series, Volume 86, 2020, p. 117 - 160.

\section{EU LAW}

1. Consolidated version of the Treaty on the Functioning of the European Union [2012] OJ C 326

2. Council Regulation 2004/139/EC on the control of concentrations between undertakings (the EC Merger Regulation) [2004] OJ L 24

3. Proposal for a Regulation of the European Parliament and of the Council on contestable and fair markets in the digital sector (Digital Markets Act) COM/2020/842 final

\section{LIST OF NATIONAL REGULATIONS, ACTS AND COURT DECISIONS}

1. Gesetz gegen Wettbewerbsbeschränkungen in der Fassung der Bekanntmachung vom 26. Juni 2013 (BGBl. I S. 1750, 3245) (German Act against Restraints of Competition)

2. German Federal Cartel Office vs. Facebook, KVR 69/19 - decision of June 23, 2020

\section{WEBSITE REFERENCES}

1. Chatillon, A.; Henno, O., Rapport d'information, Sénat $N^{\circ} 603$, [http://www.senat.fr/rap/ r19-603/r19-6030.html], p. 67, Accessed 13 April 2021

2. Europe fit for the Digital Age: Commission proposes new rules for digital platforms, Press release as of 15 December 2020, [ec.europa.eu/commission/presscorner/detail/en/ ip_20_2347], Accessed 15 March 2021

3. The Federal Court of Justice provisionally confirms the allegation of abuse of a dominant market position by Facebook, press release, [www.bundesgerichtshof.de/SharedDocs/Pressemitteilungen/DE/2020/2020080.html], Accessed 10 April 2021

\section{OTHER}

1. A new competition framework for the digital economy, Report by the Commission "Competition Law 4.0", Federal Ministry for Economic Affairs and Energy of Germany, 2019.

2. Challenges for Competition Policy in a Digitalised Economy, Study for the ECON Committee, 2015.

3. Crémer, J.; de Montjoye Y.A.; Schweitzer, H., Report Competition policy for the digital era, 2019.

4. Hoernig, S., The Digital Markets and Services Act: Context and Outlook? Policy Paper for the Institute of Public Policy Lisbon, 2021

5. Motta, M.; Peitz, M., Intervention triggers and underlying theories of harm, Expert advice for the Impact Assessment of a New Competition Tool, 2020. 
6. Privacy and competitiveness in the age of big data: The interplay between data protection, competition law and consumer protection in the Digital Economy, Preliminary Opinion of the European Data Protection Supervisor, 2014.

7. The European Proposal for a Digital Markets Act - A First Assessment, Centre on Regulation in Europe, January 2021 